\title{
O URBANISMO E DISCURSOS MODELARES DA CURITIBA CONTEMPORÂNEA
}

\author{
André de Souza Carvalho*
}

Resumo: Curitiba é uma cidade que ganhou a mídia nas últimas décadas com alcunhas de cidade de primeiro mundo, capital ecológica, metrópole de qualidade de vida privilegiada, dentre outras. Inegavelmente a cidade conseguiu destaque mundial pela divulgação e promoção de soluções urbanas “exemplares” e criativas, algumas delas mais belas e eficientes em meios propagandísticos que na prática. $\mathrm{A}$ partir da estruturação de um Instituto de Planejamento Urbano e da ação de prefeitos urbanistas, a capital paranaense sofreu modificações consideráveis e contínuas desde a década de 1970. Analisar o processo de planificação urbana de Curitiba nos últimos quarenta anos e principalmente o discurso que o legitima, assim como sua divulgação e apropriação, é o objetivo do presente texto

Palavras-chave: Curitiba; História; Planejamento Urbano; Análise do Discurso; IPPUC.

* Graduado em História pela Universidade Federal do Paraná e pesquisador de História da TV SINAL, atua na produção de conteúdo para programas e documentários que enfocam a História do Paraná, nacional e geral. 


\section{O URBANISMO E DISCURSOS MODELARES DA CURITIBA CONTEMPORÂNEA}

\section{André de Souza Carvalho}

Paradigma de cidade humanista, bem sucedida e eficientemente planejada; "cidade modelo de um país viável"; Vitrine mundial de criatividade urbana... Não faltam enunciados para legitimar Curitiba como referência exemplar de planejamento urbano no Brasil. Sua planificação é exaltada por administradores municipais, divulgada pela mídia local, nacional e até internacionalmente. É reconhecida, por muitos de seus habitantes, como possuidora de uma infra-estrutura bem estabelecida, um sistema de transporte urbano eficiente e um ambiente urbano limpo e organizado para os padrões nacionais.

Exageros, marketing e contradições à parte, o fato é que os discursos sobre Curitiba como uma cidade exemplar, modelar e idealizada - a partir de um determinado contexto marcado pela institucionalização de um planejamento urbano mais efetivo praticamente se homogeneizaram, sendo reproduzidos e reverberados em diversas esferas. A forma como esse discurso foi semeado, o território fértil no qual isso ocorreu, as situações nas quais ele foi cultivado e reproduzido e as condições para a eficácia e

\footnotetext{
1 “Cidade Modelo de um País Viável”, VEJA, 31 de março de 1993.
} 
hegemonia do mesmo serão apresentados e analisados no presente artigo.

Tendo em vista a análise do discurso no contexto do planejamento urbano de Curitiba a partir da década de 1970 até aos dias atuais, definiu-se como fontes para análise e reflexão os documentos e publicações produzidos pelo IPPUC (Instituto de Planejamento Urbano de Curitiba), Prefeitura Municipal e pelo exprefeito e governador Jaime Lerner. Também se inclui no corpus de fontes as matérias e reportagens sobre Curitiba veiculadas na imprensa e depoimentos de moradores da cidade ${ }^{2}$. Os primeiros grupos de fontes são importantes para identificação da construção e estabelecimento do discurso, por sua vez, as demais fontes (os reflexos na mídia e os depoimentos dos habitantes) revelam o quanto o discurso foi divulgado e teve uma considerável aceitação e identificação, surtindo o efeito esperado.

Para Foucault, o discurso consiste num "conjunto de regras anônimas, históricas, sempre determinadas no tempo e no espaço, que definiram, numa dada época e para uma determinada área social, econômica, geográfica ou lingüística, as condições de exercício da

${ }^{2}$ Trata-se de depoimentos de habitantes que viveram em Curitiba antes e após a implantação do Plano, contidos no volume anexo da dissertação: SANTOS, A. C. A. Memórias e cidade; depoimentos e transformação urbana de Curitiba. 19301990. Dissertação de Mestrado, Universidade Federal do Paraná, 1995. 
função enunciativa" ${ }^{3}$, afinal, ele reflete uma visão de mundo vinculada aos seus enunciadores e receptores, e assim, à sociedade em que estes vivem.

A Curitiba modelo, ecológica, européia... divulgada intensamente na mídia e assim reconhecida por boa parcela de seus habitantes, surgiu, sobretudo, a partir da década de 1970. Apesar do planejamento urbano estar presente na cidade desde a segunda metade do século XIX e de haver um certo reconhecimento do Plano desenvolvido por Alfred Agache na década de 1940, consensualmente, costuma-se atrelar a planificação urbana da capital paranaense às políticas urbanas desenvolvidas a partir das últimas quatro décadas, especialmente após o início da atuação do IPPUC Instituo de Pesquisa e Planejamento Urbano e a posse do ex-prefeito e urbanista Jaime Lerner.

O direcionamento urbano de Curitiba, a partir de então, ocorreu num contexto nacional de ascensão de forças burocráticomilitares $^{4}$ e do fortalecimento da ideologia de um planejamento racional. Apesar de possuir algumas nuances humanistas, o urbanismo que passou a inspirar o planejamento de Curitiba possuía

\footnotetext{
${ }^{3}$ FOUCAULT, M. A Arqueologia do Saber. Petrópolis, Vozes, 1972, p. 148.

4 "O regime militar acabou tendo conseqüências no desenvolvimento de Curitiba, devido ao apoio aos programas dos prefeitos nomeados." Depoimento de Ney Aminthas de Barros BRAGA. IPPUC. Memória da Curitiba urbana. Curitiba, dezembro de 1990, Depoimentos 5, p. 3.
} 
também tendências modernistas ${ }^{5}$. Acreditava-se no poder da Arquitetura e do Urbanismo para o ordenamento do espaço e sua influência no comportamento das camadas mais baixas da população.

Analisando a aplicação inicial do discurso sobre o planejamento urbano da cidade, temos os enunciadores (Lerner e IPPUC) em uma posição bastante favorável: detinham o poder político e controle administrativo da cidade; o contexto é marcado pela mudança de um pensamento tecnocrata para um mais humanista e apesar do contexto da Ditadura Militar no Brasil e o discurso possui certa reversibilidade ${ }^{6}$ ao permitir a sua apropriação pela mídia e absorção pelo cidadão, entretanto, a polissemia (a possibilidade do discurso gerar múltiplos significados) é bastante contida ao construir e instituir uma interpretação fechada sobre o desenvolvimento urbanístico de Curitiba, seus precedentes e resultados.

No caso analisado, o discurso foi enunciado pela pessoa legítima para fazê-lo, produzido em situação legítima e diante de

${ }^{5}$ SOUZA, Nelson Rosário de. Planejamento Urbano em Curitiba: Saber Técnico, Classificação dos citadinos e partilha da cidade. Rev. Sociol. Polít., Curitiba, 16, p. 107-122, jun. 2001.

${ }^{6}$ Indursky, citando Maingueneau aponta que "a prática discursiva integra a formação discursiva e os grupos sociais em cujo interior é produzido o discurso", o que garante uma reversibilidade entre o social e textual e coloca o discurso em sua função de representação. INDURSKY, Freda. A fala dos quartéis e outras vozes. Campinas: Ed. UNICAMP, 1997, p. 20. 
destinatários legítimos ${ }^{7}$, o que rendeu êxito, reprodução e apropriação. Conforme aponta Bourdieu (1996), o discurso somente é autorizado e, conseqüentemente, eficaz se for reconhecido como tal. E assim ocorreu em Curitiba.

A "Memória da Curitiba Urbana” constituíram documentos interessantes para analisar o discurso do planejamento urbano de Curitiba. Concebidas e editadas pelo IPPUC $^{8}$ e compostas por depoimentos de técnicos e presidentes que atuaram no Instituto a partir de sua criação, em 1965. Tais memórias parecem justificar a necessidade da implantação e manutenção de semelhante Instituto para o desenvolvimento e planejamento urbano da cidade, assim como procura legitimar o órgão enquanto responsável pela maior transformação pela qual Curitiba teria supostamente passado.

7 MAINGUENEAU, Dominique. Novas Tendências em análise do discurso. Campinas: Pontes, 1989

${ }^{8}$ Sobre o Instituto é interessante observar a forma como ele se auto-significa: "Os benefícios urbanos que a cidade de Curitiba recebeu nas últimas décadas tiveram uma participação efetiva dos técnicos do Instituto de Pesquisa e Planejamento Urbano de Curitiba - IPPUC. Com uma equipe especializada em planejamento urbano e realizando um trabalho voltado para o futuro, com a preocupação de resgatar a memória de tudo o que se fez no passado, o Instituto adquiriu ampla experiência em política municipal visando a resolução dos problemas urbanos. (...) O IPPUC tem participado efetivamente do cotidiano do Município, influindo diretamente nas modificações da vida curitibana, em seus aspectos físicoterritoriais e humanos". IPPUC. Curitiba - Planejamento um processo permanente. Curitiba: IPPUC, 2000. 
Produzidas durante o terceiro mandato do prefeito Jaime Lerner na prefeitura municipal de Curitiba (1989-1993) as memórias não deixam de destacar a importância de Lerner como o grande responsável pelas transformações da capital paranaense e de colocar o IPPUC enquanto principal aliado do prefeito no planejamento e execução de uma nova Curitiba. O trecho abaixo revela um pouco o tom, ou, utilizando conceitos de Maingueneau, o ethos do discurso do IPPUC, marcado por certa empolgação e um ar de vitória e realizações:

Dezembro de 1965. A cidade, ainda com os ecos do polêmico seminário "Curitiba de Amanhã", encerra o ano vendo nascer o Instituto de Pesquisa e Planejamento Urbano de Curitiba IPPUC.

Em sua tarefa de delinear o mais amplo conjunto de mecanismos que possibilitasse ordenar o processo de desenvolvimento da cidade. Ao orgão fora entregue, assim, a responsabilidade de concilar tempo e espaços urbanos para a construção de um futuro melhor aos habitantes desta cidade.

(...) A década de 70 imprime ao IPPUC a importância ainda maior. As diretrizes do planejamento urbano de Curitiba passavam do plano de idéias para o plano das ações (...) E 
nada foi em vão: Curitiba desfrutou da mais profunda transformação física, econômica e cultural de sua história ${ }^{9}$

Na seqüência, após se auto-intitular a "Sorbonne do Juveve" e elencar diversos projetos planejados e executados, o IPPUC continua:

Mas nem sempre é possível escapar de tempos sombrios! E muitas dessas experiências foram, posteriormente abandonadas ou desvirtuadas, pela incapacidade de conjugar a essência política da formação técnica com o conteúdo técnico da visão política (...) Agora, retoma-se o caminho das soluções inovadoras, para colocar Curitiba como uma cidade contemporânea do futuro. ${ }^{10}$

Nessa segunda parte do discurso é possível identificar uma certa denuncia e crítica voltada a administração municipal sem Jaime Lerner, entretanto, com o retorno do prefeito, Curitiba retomaria seu brilhante rumo ao futuro.

Atuando como o "cabeça" do IPPUC, Lerner também usou de seu poder e autoridade para produzir discursos que contribuiriam ainda mais para o fortalecimento de sua figura pública e para a importância e destaque de suas obras e trabalho como urbanista. O jovem arquiteto que havia sido indicado em 1971 para assumir a prefeitura municipal de Curitiba, fizera parte, nos anos anteriores, da

${ }^{9}$ IPPUC. Memória da Curitiba Urbana. Curitiba, dezembro de 1990, Depoimentos 5, p. VII.

${ }^{10}$ Idem, p. VIII. 
equipe que desenvolveu o Plano Diretor de Curitiba. Uma vez no comando do executivo municipal não mediu esforços para colocar o Plano em prática e divulgá-lo e afirmá-lo como necessário para Curitiba, realizado pelo bem da cidade e de seus cidadãos e não algo imposto e teorizado por tecnocratas.

Interessante observar que Lerner assumiu o comando de Curitiba e iniciou a execução do Plano em um período marcado pela tecnocracia e militarismo no Brasil. Prefeito biônico, imposto pela ditadura militar, o arquiteto e urbanista, apesar de sua legitimidade, não utilizou de um autoritarismo expresso, ao contrário, tentou camuflá-lo a partir de um discurso de alguém que pensava a cidade para o homem, que se preocupava com a qualidade de vida e o meio ambiente. $\mathrm{Na}$ construção desse discurso, visou aproximar a população dos ideais urbanísticos e receber o aval dos "curitibanos" para as transformações que seriam realizadas na cidade, afinal, seria necessário que os habitantes da cidade vislumbrassem algum sentido nas agressivas obras e transformações urbanas que seriam realizadas. Utilizando a sentença de Vinícius de Moraes "a vida é a arte do encontro", Lerner acreditava que uma vez a cidade constituindo o lócus onde desenvolve a vida das pessoas, ela deve vincular e jamais separar as funções e atividades principais de seus habitantes. Dessa forma, o prefeito-urbanista, utilizando-se de medidas simbólicas e carismáticas, procurou fazer e divulgar obras que envolveria a população. 
Ato bastante simbólico foi o fechamento da rua XV de Novembro ao tráfego de veículos, no qual Lerner utilizou de um discurso "humanista" para legitimar sua intervenção na principal rua curitibana. A sua concepção de urbanismo objetivava um meio urbano mais humano e, para isso, o habitante deveria assumir a própria cidade, ressaltando sua condição de cidadão. Dessa maneira, os espaços públicos deveriam ser democratizados e se tornarem atraentes para a população. Para Lerner:

a cidade - com todas suas funções - deve estar a serviço do homem e não o homem subordinar-se às imposições urbanas como mero expectador. (...) Em termos de abordagem, vamos encarar a cidade como uma metrópole; em termos humanos, vamos viver a cidade como uma acolhedora vila. ${ }^{11}$

A cidade deveria ser feita para o homem e não para o automóvel, afinal, já era conhecida a desintegração provocada pelas grandes avenidas nos espaços públicos citadinos, assim como a degradação de valores e referenciais significativos. Assim sendo, o centro deveria ser preservado como um local de encontro das pessoas e não dos automóveis

Entendemos que o homem tem seu lugar na cidade e que os pontos de encontro são feitos para gente e não podem ser deteriorados pelo automóvel. Não se joga fora os valores tradicionais e culturais de uma cidade, tudo aquilo que levou

${ }^{11}$ LERNER, Jaime. Discurso de posse na Prefeitura de Curitiba, março de 1971. 
anos para ser sedimentado, o prédio, a rua tradicional ou o centro da cidade. O cuidado de preparar novos pontos de encontro, proteger e melhorar aqueles que já têm sido consagrados pela população; a devolução do centro da cidade para o pedestre, a manutenção da escala humana em determinadas ruas e a criação de vários pontos de encontro traduzem essa preocupação com o homem. ${ }^{12}$

Acreditando que circulação de pessoas em pontos importantes é fundamental para que se estabeleça uma referência e a partir daí uma identificação, Lerner se preocupou com a questão da identidade e pertencimento dos habitantes com a cidade, algo que transpareceu em suas obras e discursos.

Discurso este que se reproduziu de diversas formas, sob diferentes "temáticas" sempre envolvendo a cidade, o planejamento e a mudança engendrada através dele. A ressonância das idéias, fatos e "produtos" disseminados por esse discurso "oficial” foi considerável, atingindo os meios de comunicação e a própria população, sobretudo a classe média curitibana.

Ao analisarmos, a partir da implantação do Plano Diretor, os discursos do IPPUC e do chefe do executivo de Curitiba - e seus ecos na imprensa - é visível o desejo de divulgar uma "revolução",

\footnotetext{
${ }^{12}$ LERNER, Jaime. A cidade: cenário do encontro. Roteiro do filme produzido em outubro de 1977 e apresentado em conferências em Paris e Edinburgh.
} 
desenvolvida através do planejamento urbano, desencadeadora de uma verdadeira transformação na cidade.

Torna-se interessante observar alguns trechos da reportagem de várias páginas, publicada já na década de 1970, intitulada "Curitiba. Uma experiência (ousada) que deu certo." que cita elogios e recomendações feitas a Curitiba por urbanistas internacionais e evoca o IPPUC como o "dono do milagre":

Uma cidade mais humana, onde o automóvel não recebe atenções prioritárias (...) o automóvel foi retirado do centro da cidade, para que essa área se transforme em território exclusivo de pedestres. Ruas transformam-se em "calçadões", com sorveterias, bares, bancas de revistas e canteiros de flores. E principalmente muitos bancos de jardim. (...) O enfoque humanístico dado a sua administração logo ganhou projeção nacional. (E até internacional: o engenheiro inglês Richard Scurfield publicou, numa revista francesa especializada em urbanismo, um artigo que considera a experiência curitibana em transporte de massa como um exemplo de integração inteligente, com boa dose de imaginação, entre a infraestrutura de transporte e um plano de desenvolvimento. (...) A partir do IPPUC a execução e desenvolvimento das diretrizes para o planejamento urbano curitibano foram efetivamente atribuídas a um orgão específico (...) $\mathrm{Na}$ realidade o IPPUC é muito mais do que dizem seus estatutos. É o próprio cérebro da administração municipal de Curitiba. Praticamente nada se faz de concreto sem que seja consultado. Se um incorporador deseja construir um edifício, antes de definir seu projeto, procura o IPPUC. Se os 
empresários de ônibus querem aumento de tarifa. este órgão é quem dá as faixas de reajustes. Quando o Governo Federal planeja, por exemplo, construir algo com o um centro social, o IPPUC é quem diz onde pode ser localizado. (...) O controle exercido pelo instituto é de tal forma abrangente que lhe permite acompanhar o número de passageiros transportados por ônibus, em casa viagem. ${ }^{13}$

A Revista ainda publica um depoimento de Lerner:

Uma cidade é muito mais do que um modelo de planejamento; é muito mais do que instrumento de política econômica; é muito mais que um núcleo de polarização social. A alma de uma cidade, a força vital que a faz respirar, progredir, existir, reside em cada um de seus cidadãos, em cada homem que nela aplica e esgota o sentido de sua vida. ${ }^{14}$

Fica evidente que Jaime Lerner, enquanto autoridade municipal e "autoridade" no discurso que enuncia, possui facilidade em divulgar sua ideologia e torná-la aceita e reconhecida. O discurso revela a "ideologia"15 enquanto efeito de sentido por ela ser constitutiva da prática discursiva. Para Indursky: "a ideologia no

13 "Curitiba: uma experiência (ousada) que deu certo", Revista Interior, v. 3, n. 16, mar/abr 1977, p. 7-9.

${ }^{14}$ Idem, p. 8.

${ }^{15}$ Segundo Orlandi: "Podemos compreender a ideologia como o fato de que os sentidos são fixados historicamente, em uma direção determinada”. ORLANDI, Eni Pulcinelli. A linguagem e seu funcionamento. São Paulo: Brasiliense, 1983, p. 103. 
âmbito da $\mathrm{AD}$ consiste em deslocar a relação imaginária com o mundo real (...) para o interior dos processos de significação." 16

Da mesma forma, o IPPUC adquiria poder através das transformações realizadas e principalmente pela divulgação das mesmas, Curitiba começava a ser "reconhecida internacionalmente por soluções tão próprias e ao mesmo tempo tão universais" ${ }^{17}$, afinal, "neste Instituto [IPPUC] nasceram e se desenvolveram os projetos que tornaram a cidade peculiar e renomada". ${ }^{18}$

E realmente tal discurso possibilitou o "renome" de Curitiba, materializando uma cidade que estava no plano das idéias, no imaginário, a qual, por sua vez, foi amplamente divulgada e apropriada pela mídia.

"Como vive uma grande cidade bem organizada" foi o destaque do Jornal da Tarde de 13 de junho de 1972. Em de 12 de maio de 1974, o Jornal "O Globo" destacava a matéria "Curitiba Sinal Verde para o homem". "Curitiba está no caminho certo" foi matéria do Jornal Gazeta do Povo de 07 de fevereiro de 1975 ao noticiar que Jaime Lerner havia recebido a comenda máxima do Instituto dos Arquitetos do Brasil por seus méritos de grande "interprete e realizador" das necessidades dos curitibanos, graças ao seu caráter

\footnotetext{
${ }^{16}$ INDURSKY, op. cit., p. 20.

${ }^{17}$ IPPUC. Memória da Curitiba Urbana. Curitiba, fevereiro de 1990, Depoimentos 2, p. VII.

18 IPPUC. Memória da Curitiba Urbana. Curitiba, dezembro de 1990, Depoimentos 5, p. VII.
} 
humanista e a preocupação de colocar o "homem no centro". O Jornal do Brasil de $1^{\circ}$ de abril de 1974 noticiou: "Professor de Arquitetura critica a urbanização de Brasília e louva Curitiba". Já na década seguinte, "Curitiba: um exemplo para o mundo" foi a manchete de "O Estado do Paraná" de 28 de abril de 1981.

Com uma reportagem intitulada "Uma experiência em planejamento urbano". A Revista Industria e Comércio de 09 de outubro de 1989 destacou: "Curitiba, a capital ecológica, surge no cenário nacional, e até mesmo internacional, como um modelo de cidade a ser imitado, em função, principalmente, do seu planejamento urbano - com vistas a um crescimento cada vez maior e da qualidade de vida que oferece à sua população."

Afirma Foucault ${ }^{19}$ que para descobrir como é feita a escolha de uma verdade, é necessário saber como ela foi repetida, reconduzida, deslocada "uma verdade no interior da qual nós estamos retidos, mas que é por nós incessantemente renovada." $\mathrm{E}$ assim foi feita com a "verdade" sobre a Curitiba modelo.

Em seu terceiro mandato na prefeitura municipal, Lerner muda a temática de seu discurso, o moderno e humano dá lugar ao ecológico e pós-moderno. É notável a expansão dos parques e das novas formas espetaculares de vidro, arame, acrílico e materiais inovadores. Rapidez nas ações e realizações, transformações urbanas inesperadas e de grande impacto visual caracterizaram esse novo governo. Novos "produtos urbanos" foram lançados como a Rua 24

${ }^{19}$ FOUCAULT, Michel. A ordem do discurso. São Paulo: Ed. Loyola, 1996. 
horas, o ônibus Linha Direta (ligeirinho) e as estações-tubo. Estes e outros elementos de aspectos futurísticos despontavam na "exprovinciana" Curitiba e recebiam destaque na imprensa local e nacional, revelando nuances de uma cidade que se transformava.

Os parques também adquiriram grande evidência na terceira administração Lerner, servindo funcionalmente para conter enchentes, proteger as nascentes dos rios e evitar ocupação urbana em áreas de risco. Além disso, eles proporcionaram uma nova imagem à cidade que estava sendo preparada para ser identificada e divulgada através de imagens verdejantes, naturais e ecológicas. $\mathrm{O}$ próprio logotipo da prefeitura municipal consistia uma folha verde sobreposta ao nome "Curitiba".

Em 1992, é lançado um volume "Memória da Curitiba urbana" especial. Com o título "Escola ecológica de urbanismo"20, sintetizando e ordenando todas as ações ambientalistas da prefeitura, mostrando as etapas e feitos que contribuíram para a transformação de Curitiba na capital ecológica. É interessante observar sua apresentação:

A Memória da Curitiba Urbana mudou. Estamos entrando, agora, em uma segunda fase. Vamos mostrar a partir deste número 8 os programas, projetos, idéias desenvolvidas e implantadas em Curitiba, que a transformaram em exemplo. Vamos saber por que Curitiba é o Brasil que pode dar certo.

\footnotetext{
${ }^{20}$ IPPUC. Memória da Curitiba urbana: Escola de Urbanismo Ecológico. Curitiba, v. 8, jan. 1992.
} 
(...) Capital Ecológica que começou a surgir, na prática, no último quarto de século. Vamos conhecer a Curitiba que conseguiu passar de meio metro de área verde por habitante para mais de 50 metros quadrados de área verde por habitante em 20 anos. Que mantém 16 parques e quase mil praças e bosques - importantes áreas verdes preservadas através do uso. Vamos contar como a Legislação de proteção ao meio ambiente, preocupação desde 1953, se consolidou em uma política para o meio ambiente em 1990. Vamos descobrir como o problema do lixo vem sendo equacionado. Por que optamos pela separação e reciclagem em uma parceria que envolve hoje cerca de 200 mil residências. Como surgiu e como foi desenvolvido o projeto da compra do lixo, que está modificando não só a aparência das vilas da periferia, mas mudando hábitos. Mudanças que deram a Curitiba dois prêmios internacionais. ${ }^{21}$

Decididamente, a partir de 1992, vestiu-se de verde o discurso sobre a cidade. Conectada com os eventos e discussões ecológicos da época, como a ECO-92 - grandioso evento mundial de ecologia realizado no Rio de Janeiro - a verdejante Curitiba estava pronta para provar que representava o Brasil que poderia dar certo, através de seus exemplos ecológicos:

Reconhecida internacionalmente como a terceira melhor cidade do mundo para se viver, Curitiba possui o maior índice de áreas verdes por habitante, não aceita a implantação de indústrias poluentes e adotou soluções criativas para melhorar

${ }^{21}$ Idem, p. VII. 
a vida de seus moradores. Seguramente, já a "Capital Ecológica do País". ${ }^{22}$

Ainda em 1992, é lançado "Curitiba. A Revolução Ecológica", ricamente ilustrada, a publicação exibia em imagens e dados uma cidade que aumentou mais de 20 vezes a coeficiente de área verde por habitante após ter passado por uma pré-revolução: O Plano Diretor, seguida por outras "revoluções" no transporte, cultural, social e econômica. A “Campeã mundial em coleta seletiva de lixo”, “modelo para qualquer comunidade e para qualquer economia autosustentada"23 era um "exemplo ao mundo", ao qual estaria dando uma "Lição de ecologia":

Os números, em Curitiba, são eloqüentes: (...) cidade separa o lixo orgânico dos resíduos sólidos que se prestam ao reaproveitamento ou à reciclagem. Só com o reaproveitamento do papel velho, a cidade evita o corte de 1.200 árvores por dia. Quantas árvores seriam salvas diariamente no mundo se todas as suas cidades procedessem da mesma maneira? (...) A cidade ambientalmente correta é, em primeiro lugar, aquela que desperdiça o mínimo e economiza o máximo. Pelo mesmo critério, é aquela que dá prioridade ao transporte coletivo sobre o transporte individual, evitando desperdício derivados de petróleo e

${ }^{22}$ IPPUC. Memória da Curitiba Urbana. Curitiba, junho de 1990, Depoimentos 3, p. 115.

${ }^{23}$ Curitiba: A Revolução Ecológica. Prefeitura Municipal de Curitiba. Maio de 1992, p. 117. 
poluição da atmosfera. Em Curitiba, onde a primazia do transporte público é uma realidade já há duas décadas, a economia de combustível é da ordem de $20 \%$ em relação às grandes cidades brasileiras. (...) Eis a cidade que se recarrega aquela que poupa recursos e poupa as pessoas. Este livro é uma reportagem, apenas uma reportagem, sobre o que, aos olhos do mundo, fez e faz de Curitiba o laboratório de uma experiência urbana - e humana - verdadeiramente revolucionária, a ponto de exportar soluções e invenções e de ser apontada como uma espécie de modelo para próxima década (...) de um novo milênio. Jaime Lerner. ${ }^{24}$

Como pode ser observado, o discurso sobre Curitiba e seu progresso e avanço, apesar de ter mudado de temática, permaneceu com o mesmo tom (ou ethos), quase que ufanístico, inflamado, revelador de "glórias" e enunciador de conteúdos positivados, parciais e pouco reflexivos sobre a exemplar capital brasileira de primeiro mundo:

"A repercussão mundial do urbanismo de Curitiba despertou
o orgulho de ser curitibano (...) Curitiba entrou no mapa do
mundo, com seu plano aplicado que pregava - e prega - a
integração de funções e serviços urbanos. Soluções locais,
numa até então perdida cidade de Terceiro Mundo. Nasceu a
identidade do curitibano com seu espaço de vida. O obscuro

${ }^{24}$ Idem, p. 3. 
ponto de passagem no mapa do Sul do Brasil ganhou prêmios como referência de "saber fazer" e "fazer acontecer". ${ }^{25}$

O êxito do discurso da Curitiba modelar e planejada pode ser observado na forma como a população absorveu, se identificou e continuou partilhando do discurso. Destacando os aspectos culturais de uma cidade onde "a imigração e o planejamento são dois marcos e marcas" ${ }^{26}$, o discurso sobre a "europeização" de uma Curitiba que se diferenciava do Brasil (discurso este já existente desde o final do século XIX e reafirmado em meados do século XX), surtiu muito efeito e aceitação por boa parte da população da cidade, especialmente aos descendentes de europeus, conforme pode ser percebido nos depoimentos abaixo:

Alguns manifestaram que sentem aqui em Curitiba o mesmo estilo de vida, uma mesma aparência de uma cidade de seus países de origem, da Europa, dos Estados Unidos. Há uma tendência a equiparar Curitiba a modelos de cidades de países mais desenvolvidos; (...) chegarem aqui manifestando um desagrado por terem estado no Rio e São Paulo, pela insegurança que sentiam, pelo risco, de sentirem medo (...) e acham Curitiba um modelo diferenciado em relação aos que eles andaram vendo no Rio e São Paulo, cidades que a maioria hoje nem preferem estar.

\footnotetext{
${ }^{25}$ Curitiba: Um modelo de gestão pública. Curitiba: PMC, 2000, p. 17. ${ }^{26}$ Idem, p. 6.
} 
Acho que esse talvez seja o grande mérito de Curitiba, essa condição de vida, estilo de vida; o tipo de população também. É uma cadinho de origens européias; é um estilo de vida diferenciado, que atrai (...) Não tenho encontrado nessas pessoas que passam por aqui nenhuma queixa sobre Curitiba (...) eles, ao contrário, espontaneamente, sem que sejam provocados, revelam o quanto agradou, encontrar um núcleo, uma cidade tão bem estruturada, com tudo. Há um diferencial para melhor em Curitiba, em relação a outras capitais. Um elogio a Curitiba". ${ }^{27}$

A cidade ficou mais bonita, graças a Deus tivemos ótimos prefeitos. Desde Iberê de Matos, Ivo Arzua, todos, um foi continuando o plano do outro e está dando certo nossa cidade. Uma cidade, assim, para mim, podem existir coisas muito melhores, mas eu acho que vida, como a nossa aqui, não tem. E, agora, com a ecologia e tudo, então, chamou muito a atenção. Não sei se porque o povo é mais, é muita mistura de raça, muito europeu, então criou um outro modo de pensar, não é. ${ }^{28}$

Como se observa, o discurso de uma cidade diferenciada, graças aos seus imigrantes europeus e assim, com padrão de vida de primeiro mundo, com a organização, estruturas e modo de pensar europeus foi devidamente aceito e legitimado por muitos curitibanos, atestando a eficiência de um discurso que utilizou de elementos que criassem identificação e assimilação com a população.

\footnotetext{
${ }^{27}$ SANTOS, op. cit. vol. anexo, p. 61.

${ }^{28}$ Idem, p. 96.
} 
O efeito de sentido do discurso de Lerner e do IPPUC e a aceitação e reprodução do que é veiculado na mídia revela-se evidente nos depoimentos dos curitibanos, orgulhosos do fato de viverem em uma cidade cujo planejamento "ajudou para que o resto do Brasil abrisse os olhos para o que é Curitiba" ${ }^{29}$ :

Existe, sim, uma grande transformação. Porque você veja uma coisa, a parte da urbanização, como é que se diz, ecológica, está muito mais bem cuidada, hoje, isso agrada a gente. Curitiba sempre foi uma cidade muito bonita, na parte de flores, de jardins, de tudo, e eles expandiram mais isso, houve maior expansão. ${ }^{30}$

Não querendo puxar a brasa para a nossa sardinha -, mas é realmente um transporte organizado. Tive oportunidade ainda esses dias de ler que se encontra em Curitiba, se encontrava até a semana passada em Curitiba, cerca de quarenta jornalistas de sete países europeus que vieram ver como funciona o transporte de Curitiba e uma série de outros desenvolvimentos, que passaram de nossas fronteiras; do desenvolvimento da cidade de Curitiba em termos de organização; e, termos de cidade ecológica; uma série de coisas. $^{31}$

Os relatos acima reproduzem termos e "chavões" utilizados no discurso sobre a cidade como "ecológica”, "transformação",

\footnotetext{
${ }^{29}$ Idem, p. 75.

${ }^{30}$ Idem, p. 97.

${ }^{31}$ Idem, p. 71.
} 
"urbanização", "desenvolvimento". Para Freda Indursky "o discurso, enquanto prática discursiva, trabalha para que o efeito de sentido discursivamente construído produza a ilusão de sentido único"32. Essa ilusão atingiu a boa parte dos curitibanos que, ao apropriarem desse "sentido único" que foi dado à cidade, acabaram se sujeitando a um discurso que construiu uma representação da cidade de Curitiba.

Assim como Haussmann ficou conhecido na historiografia como o renovador e revelador de uma nova Paris a partir de meados do século XIX, e da mesma forma com que Moses foi identificado como o "produtor" de uma nova e espetacular Nova Iorque. Em Curitiba, produziu-se também, a partir do Plano Diretor de Urbanismo, a história e o discurso de uma cidade que passava por uma "revolução" e se destacava ao mundo.

Conforme foi analisado, o discurso da Curitiba modelar e planejada produziu sentido na população (ou parte dela), a qual o reafirma e o torna ainda mais crível e homogêneo. "Representar a totalidade, o todo social, implica poder: implica construção de hegemonia, capacidade de convencimento, criação de consenso" ${ }^{133}$ e, de certa forma, o discurso sobre Curitiba conseguiu promover isso na mídia e nos curitibanos.

\footnotetext{
${ }^{32}$ INDURSKY, op. cit., p. 21.

${ }^{33}$ RIBEIRO, A. C. T.. As leituras da cidade. Intervenção como moderadora de mesa. In : Anais do Seminário "Repensando as políticas públicas e a ação na cidade". Rio de Janeiro : Câmara Municipal do Rio de Janeiro/IPPUR-UFRJ, 1999.
} 
A desejada mudança, muitas vezes ocorre apenas no discurso, no literal, camuflando, omitindo ou enganando o real. Algo perceptível e aplicável no caso estudado.

O discurso oficial parece apagar ou intimidar a existência de outros discursos. Indursky (1997) aponta que com a análise do discurso é possível desconstruí-lo e determinar os funcionamentos que proporcionam a instauração de uma ilusão, ela também aponta que os processos de significação contribuíam para a aceitação desse sentido único e muitas vezes ilusório.

A representação de Curitiba enquanto uma cidade modelar foi devidamente arquitetada e construída, especialmente a partir da década de 1970. A partir de então, a legitimação e divulgação de um discurso revelador de transformações e a construção de imagens espetaculares e homogêneas sobre Curitiba tornaram-se marcantes e freqüentes. Através delas é possível apreender tanto a cidade revelada no discurso quanto refletir sobre àquela ocultada por ele. Se Curitiba tornou-se (re)conhecida como uma cidade exemplar, o discurso que contribuiu para isto é tão ou mais exemplar.

\section{Fontes}

"A Revolução Pacífica de Curitiba. Administração e Serviços", Gazeta Mercantil, ano 4, n. 17, jan 1982.

“Cidade Modelo de um País Viável”. VEJA, 31 de março de 1993. 
"Curitiba. Uma experiência (ousada) que deu certo", Revista Interior, v.3, n.16, mar/abr 1977.

Curitiba: Um modelo de gestão pública. Curitiba: PMC, 2000.

Curitiba: A Revolução Ecológica. Prefeitura Municipal de Curitiba. Maio de 1992. Curitiba: Lagarto Editores, 1992.

Gazeta do Povo, Curitiba, 20 de maio de 1972. 2 Caderno; 29 de março de 1990; 16 de abril de 1995; 25 de julho de 1998.

IPPUC. 20 anos planejando Curitiba com você. 20 ANOS IPPUC 1985. Edição comemorativa

IPPUC. Memória da Curitiba Urbana. Curitiba, fevereiro de 1990, Depoimentos 2.

IPPUC. Memória da Curitiba Urbana. Curitiba, junho de 1990, Depoimentos 3.

IPPUC. Memória da Curitiba Urbana. Curitiba, dezembro de 1990, Depoimentos 5.

IPPUC. Memória da Curitiba urbana: Escola de Urbanismo Ecológico. Curitiba, v. 8, jan. 1992.

Jornal da Tarde. 13 de junho de 1972.

LERNER, Jaime. A cidade: cenário do encontro. Roteiro do filme produzido em outubro de 1977 e apresentado em conferências em Paris e Edinburgh. 
LERNER, Jaime. Discurso de posse na Prefeitura de Curitiba. março 1971.

Revista Imprensa. Julho de 1992.

Bibliografia

BOURDIEU, Pierre. A economia das trocas lingüisticas. São Paulo: EDUSP, 1996.

FOUCAULT, M. A Arqueologia do Saber. Petrópolis, Vozes, 1972.

. A ordem do discurso. São Paulo: Ed. Loyola, 1996.

INDURSKY, Freda. A fala dos quartéis e outras vozes. Campinas: Ed. UNICAMP, 1997.

MAINGUENEAU, Dominique. Novas Tendências em análise do discurso. Campinas: Pontes, 1989.

MENEZES, C. L. Desenvolvimento urbano e meio ambiente: a experiência de Curitiba. Campinas: Papirus, 1996.

OLIVEIRA, Dennison de. Curitiba e o mito da cidade modelo. Curitiba: Editora da Universidade Federal do Paraná, 2000.

ORLANDI, Eni Pulcinelli. A linguagem e seu funcionamento. São Paulo: Brasiliense, 1983.

- Análise de Discurso: princípios e procedimentos. Campinas: Pontes, 1999. 
. Discurso e Texto: formação e circulação dos sentidos. Campinas: Pontes, 2001.

PESAVENTO, Sandra. O Imaginário da Cidade: visões literárias do Urbano - Paris, Rio de Janeiro, Porto Alegre. Porto Alegre: Ed. Universidade/UFRGS, 1999.

RIBEIRO, A. C. T. 1999. As leituras da cidade. Intervenção como moderadora de mesa. In: Anais do Seminário "Repensando as políticas públicas e a ação na cidade". Rio de Janeiro: Câmara Municipal do Rio de Janeiro/IPPUR-UFRJ.

SANTOS, A. C. A. Memórias e cidade: depoimentos e transformação urbana de Curitiba. 1930-1990. Dissertação de Mestrado, Universidade Federal do Paraná, 1995.

SOUZA, Nelson Rosário de. "Planejamento Urbano em Curitiba: Saber Técnico, Classificação dos citadinos e partilha da cidade". Rev. Sociol. Polít., Curitiba, 16, p. 107-122, jun. 2001. 